\title{
MINI IMPLANTS VERSUS CONVENTIONAL DIAMETER IMPLANTS FOR 4-IMPLANT-SUPPORTED MANDIBULAR OVERDENTURES. ONE YEAR RANDOMIZED PROSPECTIVE CLINICAL AND RADIOGRAPHICAL STUDY
}

\author{
Amr Abd El Bary Mahdy Emarah*, Mohammed Omran Hamed**, \\ Inass Aboulmagd ${ }^{* * *}$ and Shahinaz Sayed Mohamed Hassan ${ }^{* * * *}$
}

\begin{abstract}
Purpose: This study aimed to evaluate clinical and radiographic outcomes of mini-implants versus conventional diameter implants for 4-implant-supported mandibular overdentures after one year.
\end{abstract}

Materials and methods: 12 edentulous patients with insufficient retention of their conventional mandibular dentures and reduced mandibular ridge width were assigned into 2 groups; group 1 (conventional implants group, control); received four conventional diameter implants using flap surgical approach, group 2 (mini-implant group): received four mini-implants in the interforaminal area of the mandible using flapless surgical approach. For both groups, implants were loaded immediately with mandibular overdentures via O-ring attachments. Plaque index, Gingival Index, probing depth, implant stability and marginal bone loss was assessed at baseline, 6 months and 12 months after overdenture insertion.

Results: The survival rates were $95.9 \%$ and $91.7 \%$ for conventional implant and min-implants groups without difference between groups. For both groups, Plaque index, gingival index and implant stability did not differ significantly between observation times. Probing depth and marginal bone loss significantly increased with passage of time. Conventional diameter group showed significantly higher plaque, gingival indices, probing depth, implant stability and marginal bone loss than mini-implant group after six and 12 months.

Conclusion: Within the limitation of this randomized trial, mini-implants may be a suitable alternative to conventional diameter implant in patients with reduced buccolingual bone thickness as it was associated with reduced Plaque index, Gingival Index, probing depth and marginal bone loss after one year. However, conventional diameter implants provided more implant stability than mini-implants.

KEYWORDS mini, conventional, overdentures

\footnotetext{
* Lecturer, Department of Removable Prosthodontics, Faculty of Dentistry, Fayoum University, Fayoum, Egypt

** Lecturer, Oral and Maxillofacial Surgery Department, Faculty of Dentistry, Beni-Suef University, Egypt

*** Assistant Professor, Department of Oral and Maxillofacial Radiology, Faculty of Dentistry, Fayoum University,

Fayoum, Egypt

**** Assistant Professor, Department of Removable Prosthodontics, Faculty of Dentistry, Beni-Suef University, Egypt.
} 


\section{INTRODUCTION}

Although two implant retained mandibular overdentures are considered the minimum standard of care for edentulous patient as they are sufficient to retain overdentures ${ }^{1,2}$, this prosthesis depends on the mucosal support. However, in patients with atrophied mandibular ridge, sensitive mucosa which is easily irritated by the pressure from the denture base, patients with sharp or knife edge ridges, sharp mylohyoid projections, an implant-supported overdentures on four implants are indicated to provide increased implant-supported, reduce mucosal support, and improve patient satisfaction and overall treatment outcome ${ }^{3-5}$. In several cases, patients exhibit reduced buccolingual bone especially in the anterior region of the mandible which usually compromise placement of conventional diameter implants unless, bone recontouring, ridge splitting or bone augmentation are performed ${ }^{6}$. This may result in increased mobility especially for elderly debilitating patients ${ }^{7}$

Mini dental implants are single piece implants used for mandibular overdentures and have a diameter ranging from 1.8 to $2.4 \mathrm{~mm}^{8}$. Compared to conventional diameter implants $(>3.4 \mathrm{~mm}$ in diameter) they are indicated in patients with increased bone resorption who had narrow residual ridges and insufficient buccolingual bone width ${ }^{6}$. These implants provide several advantages such as elimination of ridge augmentation and bone grafting procedures which may be problematic in old patients with compromised medical history ${ }^{9}$. Moreover, these implants are self-threaded into the bone and can be inserted with flapless surgical approach with minimal osteotomy size ${ }^{10}$. Mini implants are also costeffective and have fewer complications compared to conventional diameter implants ${ }^{11,12}$. Mini implants provide immediate rehabilitation and loading of the implants consequently less appointments are required $^{10}$, while conventional implants may use immediate, early or delayed loading protocols ${ }^{13}$. The minimum number of implants indicated with conventional diameter implants retaining mandibular overdentures are two, while for mini-implants are mandatory to retain overdentures to compensate for reduced implant diameter ${ }^{14}$

The biomechanical studies revealed that implant diameter may influence the stresses in the crestal bone around the implants compared to implant length ${ }^{15,16}$ and consequently may have an effect on marginal bone loss around the implants. The reduced implant diameter minimize bone to implant contact and may affect osteointegration and bone loss around implants due to implant overload ${ }^{17}$. The mini dental implants used to retain overdentures have high success rate. However, comparison of marginal bone loss and clinical parameters of mini-implants supporting mandibular overdentures with standard diameter implants is scarce in published data ${ }^{18}$. Reviewing the literature, only two studies comparing 4 mini-implants retaining implant overdentures (with O-ring attachments) with two conventional diameter implants retaining overdentures (with bar and locator ${ }^{19}$ ) or (ball attachments $)^{20}$. Another study comparing patient satisfaction and bone density of four mini-implants retaining overdentures with four conventional diameter implants. However, no studies available in the literature comparing clinical outcomes and marginal bone loss between 4-mini-implants and 4-conventional diameter implants supporting mandibular overdentures. In a systematic review ${ }^{18}$, the authors reported that mini-implant overdentures had better patient's satisfaction compared to standard diameter overdentures but the evidence was low. The authors recommended conduction of high-quality randomized controlled trials to compare mini-implants with standard diameter implants

The aim of this prospective clinical trial was to compare clinical and radiographic outcomes of mini-implants and conventional diameter implants used for 4-implant-supported mandibular overden- 
tures after one year. The null hypothesis was no difference in outcomes between mini-implants and conventional diameter implants will be obtained.

\section{MATERIALS AND METHODS}

\section{Patient sample and study design}

A sample of 12 patients (six males and six females) were selected from patients attending the Removable Prosthodontic Department for seeking and implant treatment for their mandibular edentulous ridge due to insufficient retention of their conventional mandibular dentures. The inclusion criteria are; 1) completely edentulous maxillary and mandibular ridges, 2) discomfort and biting and chewing due to presence of sharp bony ridges, 3) patients had inadequate bone width (class IV Atwood classification 21 with at least $5 \mathrm{~mm}$ buccolingual width) at the crest of the ridge and good bone width toward the basal bone. This was verified by cone beam computerized tomography performed before surgery, 3) at least $15 \mathrm{~mm}$ mandibular bone height with healthy mucosa, 4) adequate bone quality according Lekholm and Zarb classification22 5) patients able to sign an informed consent after explaining protocol and objectives of the study. Patients were excluded if they had severe metabolic disease that affect osteointegration such as diabetes mellitus, poor denture hygiene, immunosuppressive drugs, chemotherapy, or radiation therapy and smoking habits. The study protocol was approved by the local institutional ethical committee of the faculty of dentistry Beni-Suef University (Approval No FDBSUREC/09122021/MO) Removable before prothodontics

The patients were assigned in a random manner to 2 groups; group 1 (conventional implants group, control); included six participants who received four conventional diameter implants using flap surgical approach, group 2 (mini-implant group): included six participants who received four mini-implants in the interforaminal using flapless surgical protocol. For both groups, implants were loaded immediately with mandibular overdentures via O-ring attachments. Computer-generated random numbers were performed by dental personnel not included in the study, and each participant was given a number. Then allocation of patients into each two group was performed by the same person. A code list of patients in each group was prepared by research assistant not involved with in other parts of the trial. Blinding of the surgeon, and prosthodontist was not possible.

\section{Interventions}

For both groups, new maxillary and mandibular dentures were fabricated with bilateral balanced occlusal concept using semi-anatomic acrylic teeth. The mandibular dentures were replicated, then radiopaque markers were attachment at proposed implant sites (first premolars and lateral incisor areas). The duplicate dentures were used as radiographic templates during preoperative CBCT evaluation of remaining bone and the vital structures. Then radiopaque markers were replaced by metal tubes after making holes corresponding to implant positions to convert radiographic templates into surgical templates.

For conventional diameter implant group, crestal incision was made from second premolar area on the right side to the second premolar area on the left side, then a full-thickness mucoperiosteal flap was elevated buccally and lingually. Recontouring of the alveolar ridge crest was performed using crestal osteotome's to provide at least $1 \mathrm{~mm}$ buccal and lingual to the implant platform to prevent future bone loss. Drilling sequence started by pilot drills $(2 \mathrm{~mm})$ followed by drills of increasing diameter to $3.4 \mathrm{~mm}$ as the final drill. Countersinking was performed using countersinking drills. Four regular diameter implants $(3.5 \mathrm{~mm}$ in diameter, Superline, Dentium, South Korea) were inserted parallel to each other's in first premolars and lateral incisor areas with at least $35 \mathrm{~N} / \mathrm{cm}$ torque. Ball abutments were connected to the implants at $25 \mathrm{Ncm}$ torque. The flap was closed around the abutments using interrupted sutures (fig 1). 

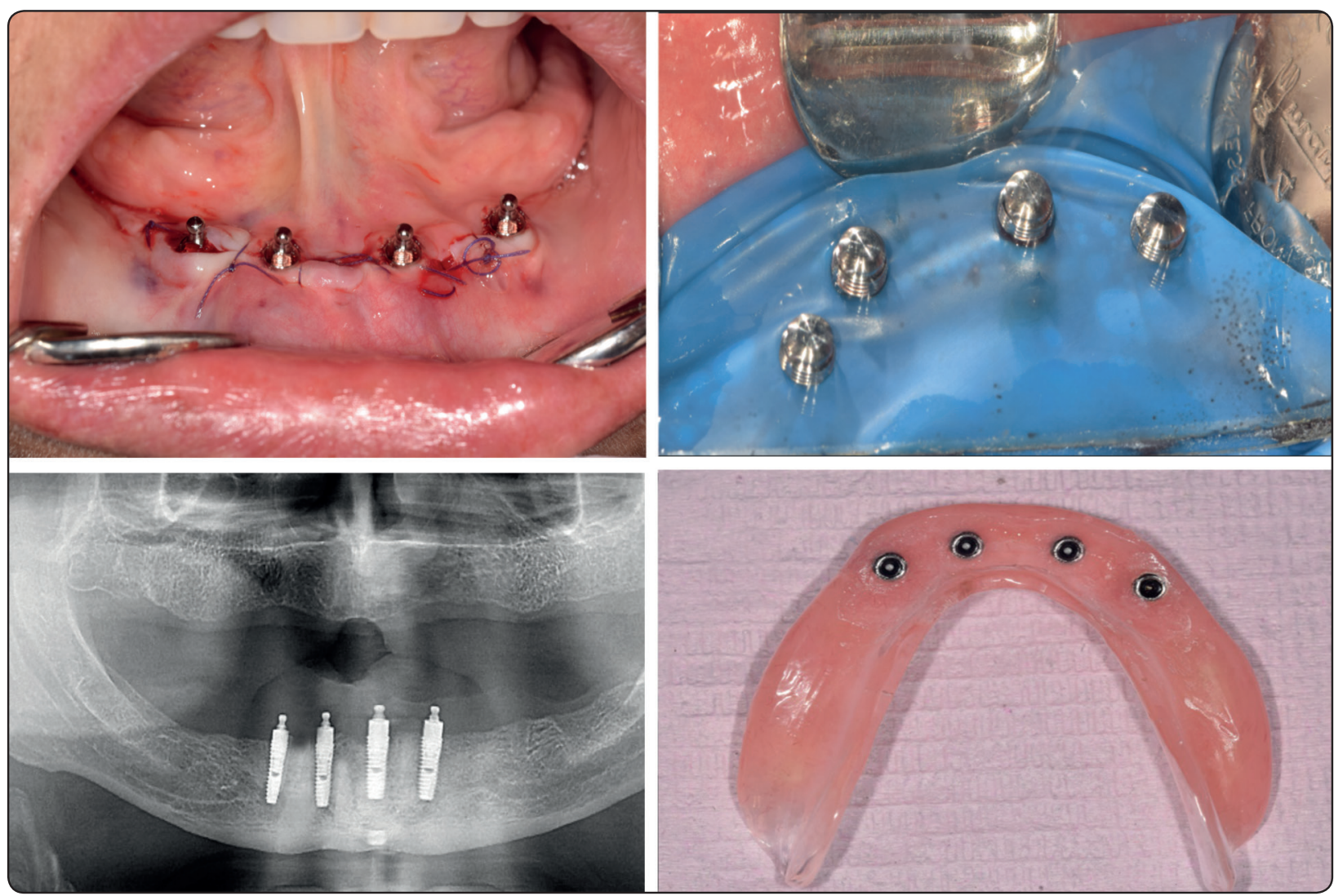

Fig. (1): Conventional diameter implant group, A; ball abutments screwed to the implants and the flap was closed, B; rubber dam sheet snapped on locator abutments and the metal housings with the $\mathrm{O} /$ ring attachment in place. C; Post-operative panoramic x-ray, D; O/ring attachments picked up to the fitting surface of the denture.

For mini-implant group, the flapless surgical protocol was followed. Four mini-dental implants (2.8mm, Slimline, Dentium, South Korea) were placed at proposed implant sites. Surgical guide was placed on the mucosa. With a periodontal probe, the implant positions were identified by bleeding points from the mucosa. A pilot drill (1.5mm) was utilized to perforate crestal cortical bone to make an initial osteotomy from 13/ to 34/ length. Each implant was inserted clockwise in the prepared osteotomy using the implant. After the implant has a resistance with bone, the mount was replaced with hand driver was then ratchet to complete implant placement with at least $35 \mathrm{~N} / \mathrm{cm}$ torque (fig 2).

For both groups, metal housings with a rubber O-ring were used. Plastic caps were cut and placed over the abutments to stabilize the metal housing and orient them parallel to each other's and also to prevent excess acrylic resin from escaping in the undercuts of ball abutments. The rubber $\mathrm{O} /$ rings were placed in the metal housings, the metal housings were snapped over ball abutments. For conventional implant group, rubber dam sheet was snapped over the ball abutments to protect the wound and the sutures. Reliefs of the mandibular dentures were performed over implant sites to create sufficient room for the housings which were picked up to the over dentures using self-cure acrylic resin immediately after implant insertion while patients closing on maxillary and mandibular overdentures in centric occlusion. The excess resin was finished and polished. For conventional diameter group, 

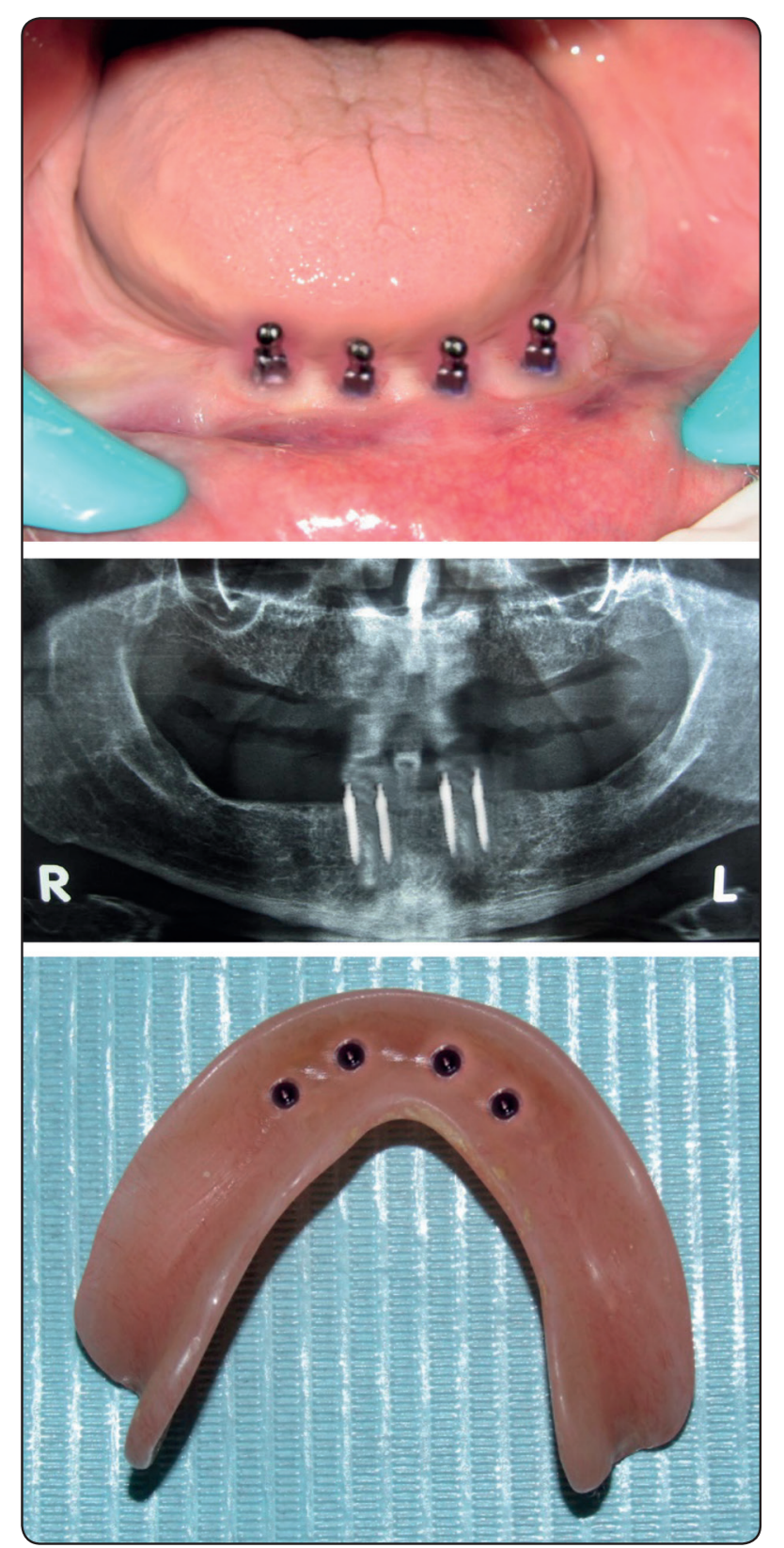

Fig. (2): Mini-implant group, A; ball abutments of the single piece mini-implants extruded in patient mouth B; Postoperative panoramic $\mathrm{x}$-ray, $\mathrm{D}$; O/ring attachments picked up to the overdenture.

relining of the denture base with hard acrylic resin was performed following an impression with a polyvinyl siloxane-based material (Zhermack, Italy). The occlusal contacts of anterior teeth were relieved to avoid implant overloading in centric and eccentric positions in the critical healing phase. Participants were instructed to eat a soft diet and perform adequate oral hygiene and denture cleansing.

\section{Evaluation of clinical and radiographical outcomes}

\section{Clinical evaluation}

Plaque index was measured using modified Mombelli index ${ }^{23}$ as follows (scores: $0=$ no plaque, 1 = plaque detected by a probe, 2 = plaque visually seen, 3 = abundance of soft matter. Gingival index was measured using modified Löe and Silness inde ${ }^{24}$. After isolation and the dryness of mucosa around implant, the mucosa around each implant surface was scored (score 0: normal, 1: mild inflammation; score 2: moderate inflammation; score 3: severe inflammation. Probing depth was measured using plastic periodontal probe. The distance from the gingival margin to the most apical Probing depth of the pocket was considered as probing depth in $\mathrm{mm}$. Plaque index, Gingival Index, and probing depth were evaluated at mesial and distal buccal and lingual implant surfaces. Implant stability was measured using Periotest device which was held at a right angle to the long axes of the implants from the buccal side. Measurements was performed three times for each implant. Periotest values (PTVs) ranged from- 9 to +9 denoted stable implant according to the manufacturer's instructions ${ }^{25}$

\section{Radiographic evaluation}

Standardized the periapical radiographic images using long cone paralleling technique was used for evaluation of marginal bone resorption at mesial and distal surface of each implant. For standardization purposes, compound bite block was used to hold the plastic film holder during subsequent film exposures to maintain the film implant distance standardized. The digital dental imaging system (Digora, Soredex) was used. Using the software of the device, the distance between the implant abutment junction (A) and bone/implant 
junction (B) was measured on both sides to present marginal bone height. Bone height was measured at base line, after 6 months and after 12 months (fig 3). Marginal bone loss was calculated as the difference between bone height after 6 months and 12 months from bone height at baseline. Mesial and distal bone loss for each implant were averaged and the mean of marginal bone loss for all implants was used for statistical analysis.

Plaque index, Gingival Index, probing depth, implant stability and marginal bone loss was assessed at baseline, 6 months and 12 months later. Clinical and radiographic outcomes were performed by 2 independent investigators blinded to treatment groups to assess the inter-examiner reliability of collected data.

\section{Statistical analysis}

IBM SPSS software version 25.0 (statistical package for social science) was used for data analysis. To test the interexaminer reliability of the data, alpha Cronbach test was used. The implant survival rate was measured using Kaplan-Meier analysis, the log rank test was used to compare survival rates between groups. Shapiro Wilk test was used to detect the normal distribution of the data. The nonparametric data (Plaque and Gingival Indices) were compared between observation times using Friedman test and Wilcoxon signed ranks test for pairwise comparisons. Between groups comparisons of plaque and gingival indices were done by Mann-Whitney test. The parametric data (probing depth, implant stability, and marginal bone loss) were compared between observation times using Repeated Measures ANOVA followed by Bonferroni multiple comparisons. Between group comparisons of probing depth, implant stability, and marginal bone loss was made using student t-test. The level of significance was adjusted at $p<.05$

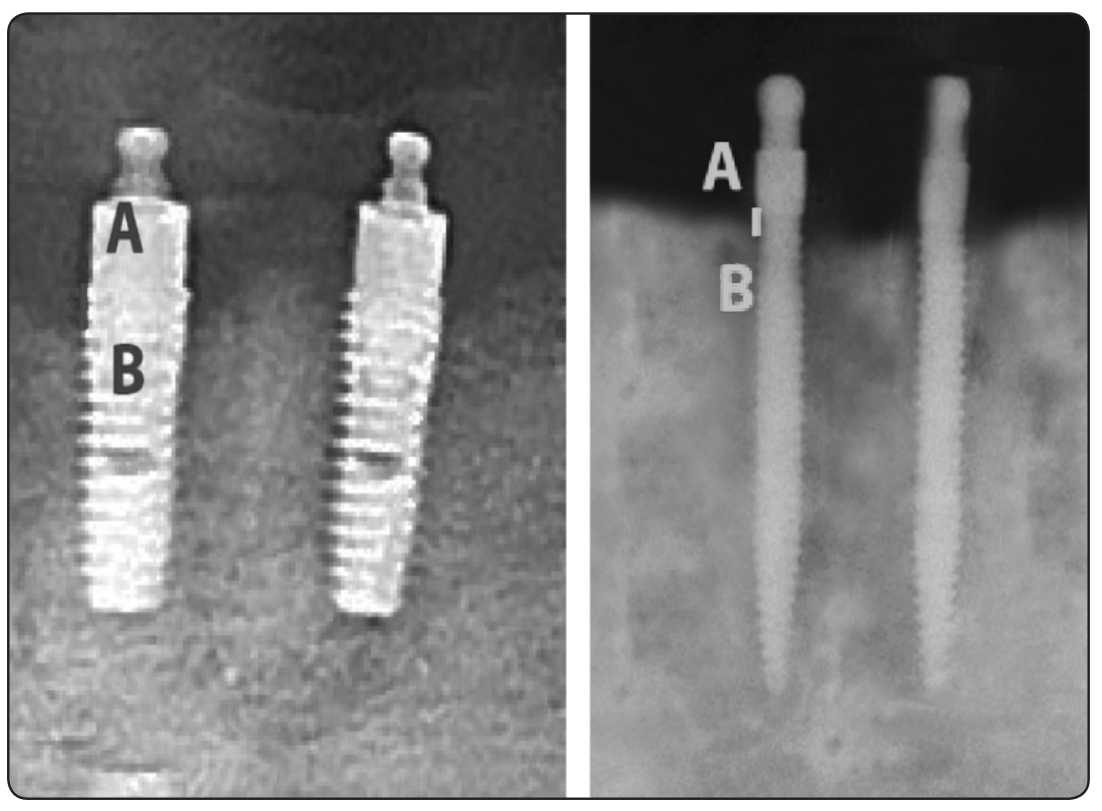

Fig. (3): Measurement of marginal bone loss for both groups. A; implant abutment junction, $\mathrm{B}$; bone to implant contact. 


\section{RESULTS}

One implant in the conventional diameter group (4.1\%) and 2 implants (in one patient) in the mini-implant group $(8.3 \%)$ failed in the first 6 months after loading resulting in $95.9 \%$ and $91.7 \%$ implant survival rates in conventional implant and min-implants group respectively. Fig 4 shows Kaplan Mayer analysis of implant survival rates in both groups. No difference in survival between groups was detected (log rank test, $\mathrm{p}=.645$ ). In both groups, the failed fixtures were retrieved and the overdentures were relined and were left to be retained by three implants (on the conventional diameter group) and by two implants in (the miniimplant group). The patients with failed implants with excluded from the study and data analysis were completed for the rest of the patients without affecting the results as the study was conducted according to "the intention to treat principal". Comparison of the reliability of clinical and radiographical data obtained by the examiners was tested by $\alpha$-Cronbach test. All correlation coefficients for clinical and radiographical data were $>80 \%$ which means that these data have a good agreement between examiners, and all data were reliable.

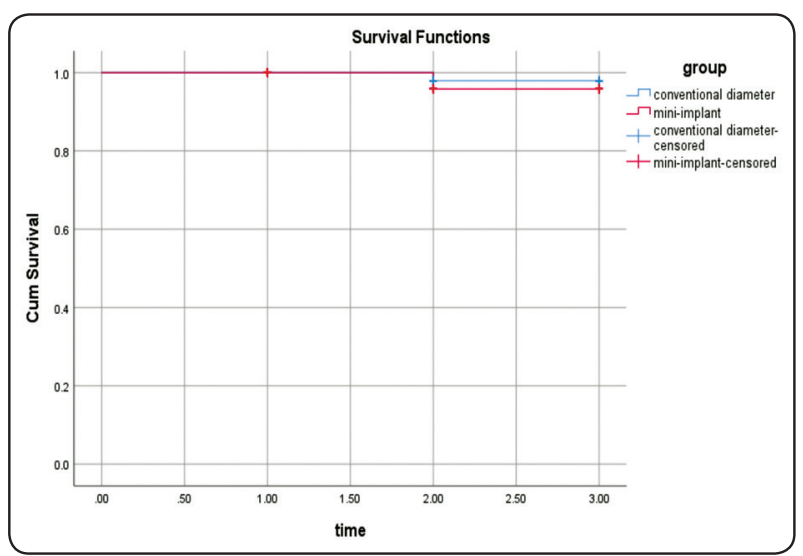

Fig. (4): Kaplan Mayer analysis of implant survival rates in both groups.
Comparison of clinical (Plaque index, Gingival Index, probing depth, and implant stability) and radiographical (marginal bone loss) data between conventional diameter implant and mini-implant overdentures at different time intervals and between different intervals for each group is presented in table 1. For both groups, plaque and gingival index did not differ significantly between observation times. Multiple comparison of plaque and gingival indices were presented in table 2. For plaque index, no significant difference between groups was observed at baseline. However, conventional diameter group showed significantly higher plaque indices than mini-implant group after six and 12 months. Gingival Index was significantly higher with conventional diameter group than mini-implant group at all observation times.

For both groups, probing depth significantly increased with passage of time (table 1). Pairwise comparisons of probing depth between each two observation times are presented in (table 2). For both groups there was a significant difference in probing depth between each two observation times. Conventional diameter group recorded significant higher pocket depth than mini-implant group at all observation times. For both groups, Periotest values did not significantly differ between observation times. However conventional diameter group showed significantly lower Periotest values (higher implant stability) than mini-implant group at all observation times. For both groups, bone loss increased from six months to 12 months (table 1). Pairwise comparisons of bone loss between each 2-time intervals are showed in (table 2). Conventional diameter group showed significantly higher bone resorption than mini-implant group after six and 12 months. 
TABLE (1): Clinical and radiographic parameters of conventional diameter implant and mini-implant overdentures at different time intervals

\begin{tabular}{|c|c|c|c|c|}
\hline & $\begin{array}{c}\text { Base line } \\
\text { (Overdenture } \\
\text { insertion) }\end{array}$ & $\begin{array}{c}6 \text { months after } \\
\text { overdenture } \\
\text { insertion }\end{array}$ & $\begin{array}{c}12 \text { months after } \\
\text { overdenture } \\
\text { insertion }\end{array}$ & $\begin{array}{l}\text { Freidman test } \\
\quad \text { ( } p \text { value) }\end{array}$ \\
\hline \multicolumn{5}{|l|}{ Plaque index } \\
\hline $\begin{array}{l}\text { Conventional implant } \\
\text { Median (Mini-maxi) }\end{array}$ & $.00(.00-0.0)$ & $1.0(0.5-1.5)$ & $1.25(0.75-1.5)$ & .12 \\
\hline $\begin{array}{l}\text { Mini-implant Median } \\
\text { (Mini-maxi) }\end{array}$ & $.00(.00-0.0)$ & $.50(.00-1.0)$ & $.75(.00-1.0)$ & .11 \\
\hline Mann-Whitney test & 1.00 & $.025^{*}$ & $.036^{*}$ & \\
\hline \multicolumn{5}{|l|}{ Gingival index } \\
\hline $\begin{array}{l}\text { Conventional implant } \\
\text { Median (Mini-maxi) }\end{array}$ & $1.00(.50-1.25)$ & $1.1(0.5-1.2)$ & $1.25(0.75-1.5)$ & .29 \\
\hline $\begin{array}{l}\text { Mini-implant Median } \\
\text { (Mini-maxi) }\end{array}$ & $.25(.00-0.50)$ & $.25(.00-1.0)$ & $.50(.00-1.0)$ & .53 \\
\hline Mann-Whitney test & $.040 *$ & $.018 *$ & $.013^{*}$ & \\
\hline \multicolumn{5}{|l|}{ Probing depth } \\
\hline $\begin{array}{l}\text { Conventional implant } \\
\text { Mean } \pm \text { St }\end{array}$ & $1.3 \pm .41$ & $1.8 \pm .52$ & $2.1 \pm .74$ & $.002 *$ \\
\hline $\begin{array}{l}\text { Mini-implant } \\
\text { Mean } \pm \text { St }\end{array}$ & $.95 \pm .35$ & $1.2 \pm .34$ & $1.5 \pm .25$ & $.004 *$ \\
\hline Mann-Whitney test & $.032 *$ & $.019 *$ & $.002 *$ & \\
\hline Implant stability & & & & \\
\hline $\begin{array}{l}\text { Conventional implant } \\
\text { Mean } \pm \text { St }\end{array}$ & $-4.5 \pm 1.1$ & $-4.4 \pm 1.2$ & $-4.6 \pm 1.5$ & .158 \\
\hline $\begin{array}{l}\text { Mini-implant } \\
\text { Mean } \pm \text { St }\end{array}$ & $-2.5 \pm 1.3$ & $-2.7 \pm 1.2$ & $-2.6 \pm 1.4$ & .254 \\
\hline Mann-Whitney test & $.037 *$ & $.039 *$ & $.041^{*}$ & \\
\hline Marginal bone loss & & & & \\
\hline $\begin{array}{l}\text { Conventional implant } \\
\text { Mean } \pm \text { St }\end{array}$ & - & $1.2 \pm .39$ & $1.7 \pm .29$ & $.028^{*}$ \\
\hline $\begin{array}{l}\text { Mini-implant } \\
\text { Mean } \pm \mathrm{St}\end{array}$ & - & $0.62 \pm .31$ & $1.1 \pm 0.42$ & $.023 *$ \\
\hline Mann-Whitney test & - & $.006^{*}$ & $.005^{*}$ & \\
\hline
\end{tabular}

Mini: minimum, maxi: maximum, St: standard deviation. *: p is significant at 5\% level. 
TABLE (2): Results of pair-wise comparison between time intervals for conventional diameter and miniimplant overdentures. Value in each cell denotes p values of Wilcoxon sign ranks test (for plaque and gingival indices) and $\mathrm{p}$ values of paired samples t-test (for pocket depth, implant stability and bone loss)

\begin{tabular}{|c|c|c|c|}
\hline & $\begin{array}{c}\text { Base line } \\
\text { (Overdenture insertion) }\end{array}$ & $\begin{array}{c}6 \text { months after overdenture } \\
\text { insertion }\end{array}$ & $\begin{array}{c}12 \text { months after } \\
\text { overdenture insertion }\end{array}$ \\
\hline \multicolumn{4}{|c|}{$\begin{array}{l}\text { Plaque index } \\
\end{array}$} \\
\hline Conventional implant & .37 & .33 & .51 \\
\hline Mini-implant & .59 & .28 & .31 \\
\hline \multicolumn{4}{|c|}{ Gingival index } \\
\hline Conventional implant & .74 & .43 & .35 \\
\hline Mini-implant & .48 & .26 & .23 \\
\hline \multicolumn{4}{|c|}{ Probing depth } \\
\hline Conventional implant & $.025^{*}$ & $.022^{*}$ & $.012^{*}$ \\
\hline Mini-implant & $.027^{*}$ & $.013^{*}$ & $.015^{*}$ \\
\hline \multicolumn{4}{|c|}{ Implant stability } \\
\hline Conventional implant & .33 & .24 & .18 \\
\hline Mini-implant & .19 & .40 & .32 \\
\hline \multicolumn{4}{|c|}{ Marginal bone loss } \\
\hline Conventional implant & - & - & $.017^{*}$ \\
\hline Mini-implant & - & - & $.015^{*}$ \\
\hline
\end{tabular}

$P$ is significant at .05

\section{DISCUSSION}

For standardization between the two groups, O-ring attachment was selected for conventional diameter group as mini-implants are supplied with O-ring attachments. Moreover, immediate loading protocol was used in the conventional diameter group and mini-implants are single piece and are designed for immediate loading. To avoid selection bias, all patients were selected with reduced buccolingual alveolar width, then randomized blindly and allocated in the treatment groups. This was performed to avoid the shortcoming of another study $^{6}$ in which the authors selected patients with thin ridges to be included in the mini-implant group and the patients was normal ridge width to be included in the conventional diameter group. This necessitates flap reflection in the conventional diameter group for bone recontouring. The direct intraoral pickup of the attachment was used as it showed superior results compared to the indirect technique from the aftercare perspective ${ }^{26}$.

In this study, the survival rate was $95.9 \%$ and 91.7\% for conventional implant and min-implants group respectively. One implant failure occurred in the conventional diameter group and the two fixtures did not integrate in the mini-implant group. In agreement with this observation, Temizel et al. ${ }^{6}$ reported one conventional implant after 1.5 years. However, the authors reported no implant failures in the mini-implant group. The survival rate did not significantly differ between groups. Similarly, Mundt et al ${ }^{7}$ reported no difference in implant survival rates between mini-dental implants and conventional dental implants. 
For both groups, Plaque index, gingival index did not differ significantly between observation times. This may reflect the more ability to clean the smooth ball attachments during wearing and removal of the dentures. A similar finding was also noted in other study $^{6}$ in which the authors reported no significant difference in plaque and bleeding scores after 3, 6, 12, and 24 months. Conversely, Elsyad et al. ${ }^{11,27}$ found a significant increase in plaque and gingival scores after six and 12 months. The difference in the results could be attributed to the difference in oral hygiene practice of the patients between studies. However, conventional diameter group showed significantly higher plaque and gingival indices compared to mini-implant group. The increased plaque scores in the conventional diameter group could be attributed to the larger diameter for attachment which may enhance more plaque retention than the small diameter mini-implant balls. Another explanation could be attributed to the flap surgery in the conventional diameter group which may discourage the patients to perform adequate oral hygiene to avoid pain in the surgical site even after complete healing of the soft tissue occurs. The increased plaque scores the conventional diameter group compared to mini-implant group was in line with finding of de Souza et al. ${ }^{20}$ who found that 4 mini-implants, 2 mini-implants retained mandibular overdentures was associated with a significantly lower plaque index compared conventional diameter 2 implants at baseline and after 6 and 12 months. The increased plaque index could be responsible for increased gingival index in the conventional diameter group as plaque accumulation usually associated with peri-implant mucosal inflammation.

For both groups, probing depth significantly increased with passage of time. The increased probing depths with time may be due to increased bone resorption to evaluate mucosal enlargement around the implants ${ }^{28}$. Conventional diameter group had higher probing depth than mini-implant group. The cause of this finding may be due to the increased bone resorption in the conventional diameter group compared to implant mini-implant group. Also flap reflection in the conventional group and suturing may increase probing depth. In contrast the single piece mini-implants may provide gap free connection with optimum mucosal barrier free of bacterial accumulation that may protect soft tissue and allow establishment of a tissue collar overlapping the bone implant interface ${ }^{29}$. The increased probing depth in the conventional diameter group is in agreement with the finding of another study ${ }^{6}$ which is also reported that probing depths around the conventional dental implants were significantly higher than those around the mini-dental implants.

For both groups, implant stability did not differ significantly between observation times. This may be due to all implants are inserted in the interforaminal area of the mandible which characterized by increased bone quality and density. Moreover, mini-implants were reported to be associated with increased bone density (in Hounsfield units) after implantation due to the auto advance technique and bone compression used during implant placement ${ }^{6}$. However, conventional diameter group showed significantly higher implant stability than miniimplant group after six and 12 months. This could be attributed to the increased implant diameter which was associated with increased surface area of the implants and increase bone to implant contact which may be associated with increased implant stability comparable to mini-implants due to the reduced implant diameter and reduce the surface area of mini-implants. Similarly, Temizel al. ${ }^{6}$ reported that Periotest values at baseline then after six months of overdenture insertion were significantly higher for the conventional diameter implants than for the mini-implants.

For both groups, bone loss increased with passage of time. This could be a result of unavoidable time dependent bone loss that is common around implant due to wound healing reorganization of bone, and bone response to increased occlusal load ${ }^{30}$. For conventional diameter implant, most amount of 


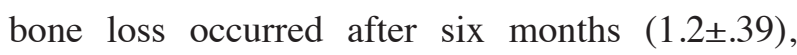
however four mini-implants nearly equal amount of bone resorption occurs after six months $(0.62 \pm .31)$

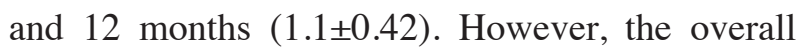
bone loss in both groups did not exceed the normal values for resorption reported in the literature after one year which is $1.2 \mathrm{~mm}$ in the first year ${ }^{31-35}$.

It was interesting to find that conventional diameter group showed significantly higher marginal bone loss than mini-implant group after six and 12 months. This may be due to several factors. Firstly, the flapless surgical approach used for implant placement has minimum disruption of the mucoperiosteum so it preserves bone blood supply of the peri-implant crestal region ${ }^{36-38}$. Secondly, the auto advance technique used from implant insertion may cause auto compression of bone which increase one ministry around mini-implants compared to conventional diameter implants which may reduce crestal bone loss. In line with this finding, Temizel et al. ${ }^{6}$ reported significant increase in the mean bone density 6 months after implantation in the patients with mini-implants than conventional diameter implants. Thirdly, the implants circumference for conventional diameter implant significantly greater values of mini-implants. Consequently, percutaneous mucosal exposure is lower in min-implants, thus implant-gingival attachment is exposed to bacterial infiltration ${ }^{39}$. Finally, the O-ring attachments with mini-implants had a dampening effect, prevent the direct transfer of the occlusal load from the denture through the implant into the surrounding bone. In line with this explanation, it was founded that overdenture retained by mini-implants requires more denture linings than overdentures retained by conventional diameter implants ${ }^{6}$. This may reflect the increased mucosal supported and subsequent increased ridge resorption (reduced implant-support, and the reduced load transmitted to the implants) compared to conventional diameter implants may be the cause for reduced bone loss in the mini-implant group. Finally, the results of this study did not support the finding of biomechanical invitro studies which suggest that the largest possible implant diameter should be used to reduce stresses around implants supporting mandibular overdenture ${ }^{40,41}$. This may be attributed to the difference between laboratory and clinical settings. The lack of standardization of surgical protocol for both groups could be considered a limitation in this study. However, a flap should be reflected in the conventional diameter group to perform bone recontouring as all included patients had a thin/knife edge ridge. On the other hand the standardized protocol for mini-implants is the flapless approach as there is no need to reflect a flap. Among other limitations is the small patient sample and the short follow up period. All these factors should be considered in future research.

\section{CONCLUSION}

Within the limitation of this short-term randomized study, regarding the small sample size, miniimplants may be a suitable alternative to conventional diameter implant in patients with reduced buccolingual bone thickness as it was associated with reduced Plaque index, Gingival Index, probing depth and marginal bone loss after one year. However, conventional diameter implants provided more implant stability than mini-implants.

\section{REFERENCES}

1. Feine JS, Carlsson GE, Awad MA, Chehade A, Duncan WJ, Gizani S, Head T, Heydecke G, Lund JP, MacEntee M, Mericske-Stern R, Mojon P, Morais JA, Naert I, Payne AG, Penrod J, Stoker GT, Tawse-Smith A, Taylor TD, Thomason JM, Thomson WM, Wismeijer D. The McGill consensus statement on overdentures. Mandibular twoimplant overdentures as first choice standard of care for edentulous patients. Gerodontology 2002; 19: 3-4.

2. Thomason JM. The use of mandibular implant-retained overdentures improve patient satisfaction and quality of life. J Evid Based Dent Pract 2010; 10: 61-63.

3. Cordaro L, di Torresanto VM, Petricevic N, Jornet PR, Torsello F. Single unit attachments improve periimplant soft tissue conditions in mandibular overdentures supported by four implants. Clin Oral Implants Res 2013; 24: 536-542. 
4. Elsyad MA, Alokda MM, Gebreel AA, Hammouda NI, Habib AA. Effect of two designs of implant-supported overdentures on peri-implant and posterior mandibular bone resorptions: a 5-year prospective radiographic study. Clinical oral implants research 2017; 28: e184-e192.

5. Elsyad MA, Hegazy SA, Hammouda NI, Al-Tonbary GY, Habib AA. Chewing efficiency and electromyographic activity of masseter muscle with three designs of implantsupported mandibular overdentures. A cross-over study. Clin Oral Implants Res 2014; 25: 742-748.

6. Temizel S, Heinemann F, Dirk C, Bourauel C, Hasan I. Clinical and radiological investigations of mandibular overdentures supported by conventional or mini-dental implants: A 2-year prospective follow-up study. J Prosthet Dent 2017; 117: 239-246 e232.

7. Mundt T, Schwahn C, Stark T, Biffar R. Clinical response of edentulous people treated with mini dental implants in nine dental practices. Gerodontology 2015; 32: 179-187.

8. Griffitts TM, Collins CP, Collins PC. Mini dental implants: an adjunct for retention, stability, and comfort for the edentulous patient. Oral Surg Oral Med Oral Pathol Oral Radiol Endod 2005; 100: e81-84.

9. Christensen GJ. The 'mini'-implant has arrived. J Am Dent Assoc 2006; 137: 387-390.

10. Balkin BE, Steflik DE, Naval F. Mini-dental implant insertion with the auto-advance technique for ongoing applications. J Oral Implantol 2001; 27: 32-37.

11. Elsyad MA, Gebreel AA, Fouad MM, Elshoukouki AH. The clinical and radiographic outcome of immediately loaded mini implants supporting a mandibular overdenture. A 3-year prospective study. J Oral Rehabil 2011; 38: 827834.

12. Elsyad MA. Patient satisfaction and prosthetic aspects with mini-implants retained mandibular overdentures. A 5-year prospective study. Clin Oral Implants Res 2016; 27 : 926-933.

13. Misch C. Rationale for dental implants. In: Misch CE (ed). Contemporary Implant Dentistry, ed 3. St Louis: . Mosby 2008: 3-25.

14. Sohrabi K, Mushantat A, Esfandiari S, Feine J. How successful are small-diameter implants? A literature review. Clin Oral Implants Res 2012; 23: 515-525.

15. Ding X, Liao SH, Zhu XH, Zhang XH, Zhang L. Effect of diameter and length on stress distribution of the alveolar crest around immediate loading implants. Clin Implant Dent Relat Res 2009; 11: 279-287.

16. Faegh S, Muftu S. Load transfer along the bone-dental implant interface. J Biomech 2010; 43: 1761-1770.

17. Zweers J, van Doornik A, Hogendorf EA, Quirynen M, Van der Weijden GA. Clinical and radiographic evaluation of narrow- vs. regular-diameter dental implants: a 3-year follow-up. A retrospective study. Clin Oral Implants Res 2015; 26: 149-156.

18. Sivaramakrishnan G, Sridharan K. Comparison of patient satisfaction with mini-implant versus standard diameter implant overdentures: a systematic review and metaanalysis of randomized controlled trials. Int J Implant Dent 2017; 3: 29.

19. Persic S, Celic R, Vojvodic D, Petricevic N, Kranjcic J, Zlataric DK, Celebic A. Oral Health-Related Quality of Life in Different Types of Mandibular Implant Overdentures in Function Longer Than 3 Years. Int J Prosthodont 2016; 29: 28-30.

20. de Souza RF, Ribeiro AB, Della Vecchia MP, Costa L, Cunha TR, Reis AC, Albuquerque RF, Jr. Mini vs. Standard Implants for Mandibular Overdentures: A Randomized Trial. J Dent Res 2015; 94: 1376-1384.

21. Atwood DA. Bone loss of edentulous alveolar ridges. J Periodontol 1979; 50: 11-21.

22. Lekholm U, Zarb G. Patient selection and preparation. In: Branemark PI, Zarb G, Albrektsson T, eds. Tissue integrated prosthesis: osseointegration in clinical dentistry. Chicago. Quintessence Publishing Co. Inc. 1985: 199-209.

23. Mombelli A, van Oosten MA, Schurch E, Jr., Land NP. The microbiota associated with successful or failing osseointegrated titanium implants. Oral Microbiol Immunol 1987; 2: 145-151.

24. Loe H, Silness J. Periodontal Disease in Pregnancy. I. Prevalence and Severity. Acta Odontol Scand 1963; 21: 533-551.

25. Olive J, Aparicio C. Periotest method as a measure of osseointegrated oral implant stability. Int J Oral Maxillofac Implants 1990; 5: 390-400.

26. Nissan J, Oz-Ari B, Gross O, Ghelfan O, Chaushu G. Longterm prosthetic aftercare of direct vs. indirect attachment incorporation techniques to mandibular implant-supported overdenture. Clin Oral Implants Res 2011; 22: 627-630. 
27. ELsyad MA, Ghoneem NE, El-Sharkawy H. Marginal bone loss around unsplinted mini-implants supporting maxillary overdentures: a preliminary comparative study between partial and full palatal coverage. Quintessence Int 2013; 44: 45-52.

28. ELsyad MA, Denewar BA, Elsaih EA. Clinical and Radiographic Evaluation of Bar, Telescopic, and Locator Attachments for Implant-Stabilized Overdentures in Patients with Mandibular Atrophied Ridges: A Randomized Controlled Clinical Trial. The International journal of oral \& maxillofacial implants 2018; 33: 1103-1111.

29. Omran M, Abdelhamid A, Elkarargy A., Sallom M. Mini-Implant Overdenture Versus Conventional Implant Overdenture (A Radiographic and Clinical Assessments). 2013; 9: 89-97.

30. Hekimoglu C, Anil N, Cehreli MC. Analysis of strain around endosseous dental implants opposing natural teeth or implants. J Prosthet Dent 2004; 92: 441-446.

31. Albrektsson T, Zarb G, Worthington P, Eriksson AR. The long-term efficacy of currently used dental implants: a review and proposed criteria of success. Int J Oral Maxillofac Implants 1986; 1: 11-25.

32. Albrektsson T, Zarb GA. Current interpretations of the osseointegrated response: clinical significance. Int J Prosthodont 1993; 6: 95-105.

33. Zarb GA, Albrektsson T. Consensus report: towards optimized treatment outcomes for dental implants. J Prosthet Dent 1998; 80: 641 .
34. van Steenberghe D, Quirynen M, Naert I, Maffei G, Jacobs R. Marginal bone loss around implants retaining hinging mandibular overdentures, at 4-, 8- and 12-years follow-up. J Clin Periodontol 2001; 28: 628-633.

35. Chung DM, Oh TJ, Lee J, Misch CE, Wang HL. Factors affecting late implant bone loss: a retrospective analysis. Int J Oral Maxillofac Implants 2007; 22: 117-126.

36. Ahn MR, An KM, Choi JH, Sohn DS. Immediate loading with mini dental implants in the fully edentulous mandible. Implant Dent 2004; 13: 367-372.

37. Bulard RA, Vance JB. Multi-clinic evaluation using minidental implants for long-term denture stabilization: a preliminary biometric evaluation. Compend Contin Educ Dent 2005; 26: 892-897.

38. Jeong SM, Choi BH, Li J, Kim HS, Ko CY, Jung JH, Lee HJ, Lee SH, Engelke W. Flapless implant surgery: an experimental study. Oral Surg Oral Med Oral Pathol Oral Radiol Endod 2007; 104: 24-28.

39. Flanagan D. Implant-supported fixed prosthetic treatment using very small-diameter implants: a case report. J Oral Implantol 2006; 32: 34-37.

40. Elsyad MA, Elhddad AA, Khirallah AS. The effect of implant diameter on strain around implants retaining a mandibular overdenture with Locator attachments: An in vitro study. Dent Mater J 2016; 35: 938-945.

41. Coelho Goiato M, Pesqueira AA, Santos DM, Haddad MF, Moreno A. Photoelastic stress analysis in prosthetic implants of different diameters: mini, narrow, standard or wide. J Clin Diagn Res 2014; 8: ZC86-90. 